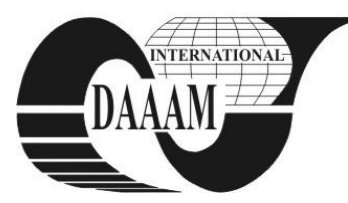

Annals of DAAAM for 2011 \& Proceedings of the 22nd International DAAAM Symposium, Volume 22, No. 1, ISSN 1726-9679 ISBN 978-3-901509-83-4, Editor B. Katalinic, Published by DAAAM International, Vienna, Austria, EU, 2011 Make Harmony between Technology and Nature, and Your Mind will Fly Free as a Bird Annals \& Proceedings of DAAAM International 2011

\title{
MULTICRITERIA OPTIMIZATION OF PLANETARY SYSTEMS
}

\author{
MIHAILIDIS, A[thanassios] K[onstantinos] \& PUPAZA, C[ristina]
}

\begin{abstract}
The study deals with the optimization of the rim thickness of the ring of a high-ratio planetary system with straight gears. In order to reduce the weight and to increase the maximum transmittable torque a new design strategy, driven by simulation and optimization is applied. The geometry of the gears was generated using a numerical procedure which takes into account the geometrically correct form of the flank. The mesh on the active flanks, as well as in the area of the tooth foot was fine, allowing the accurate calculation of both flank pressure and foot stress. Improved solutions were found. Based on a limited number of simulations many design variants were generated and various optimization criteria were fulfilled.

Key words: optimization, rim, thickness, torque, gears
\end{abstract}

\section{INTRODUCTION}

Planetary gear transmissions are widely used in machine design mainly due to the internal power splitting and the resulting high load carrying capacity. Aiming to increase the, a lot of work employing the Finite Element Analysis (FEA) has been reported in recent literature. Most of these studies address two major issues: the geometry of the tooth root fillet (Hebbal et al., 2009) and the rim thickness (Nan \& Zang, 2008). Novel gear root fillets were designed (Kapelevich et al., 2003) in order to minimize the stress and improve the strength of the gear. The influence of the rim thickness on the load carrying capacity has been extensively studied, but only for external gears (Winter \& Podlesnik, 1984). Later, the rim thickness of internal gears was considered for stress calculation (Jahn, 1997), (Linke et al. 2005). In order to avoid modelling difficulties, most authors either consider a simplified tooth profile, or they employ a rather coarse mesh. The drawback of these simplifications is that the stress field in the foot fillet area and the pressure on the mating flanks cannot be concurrently studied. Furthermore, no multi-optimization procedure has been applied, although FEA is extensively used. On the other hand, stress calculations of the planetary systems are conducted using formulae developed by the known DIN3990:1987 and ISO 6336:1996 standards.

The current study presents a combination of multi-criteria optimization techniques employed in order to reduce the weight and to increase the maximum transmissible torque of a simple high-ratio planetary system with straight gears. The geometry of the gears was generated using a numerical procedure which takes into account the manufacturing process. The mesh on the active flanks, as well as in the area of the tooth foot fillet was fine enough, allowing the accurate calculation of both flank pressure and foot stress. Improved solutions were found.

\section{PROBLEM STATEMENT}

\subsection{Optimization goals}

The optimization goals are to minimize the total weight for a given power rating and to determine the minimum rim thickness of the ring gear and of the planets.

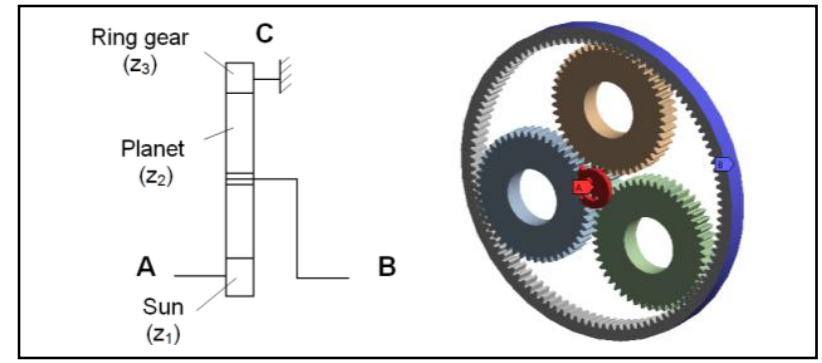

Fig. 1. Schematic view of the planetary system

The initial transmittable torque was considered to be known. The target was to find the maximum value of the input torque the assembly can withstand for a given weight. For all these calculations the safety factor was set to 1 , with respect to the allowable stress. The lay-out of the planetary system is shown in Figure 1. It consists of a sun gear, three planetary gears attached to a carrier and a ring gear. All gearings are assumed error-free. Table 1 contains the main gear dimensions, where symbols are according to ISO 6336:1996 standard.

\begin{tabular}{|c|c|c|c|c|c|c|}
\hline $\begin{array}{c}\text { Gear } \\
\text { dimensions }\end{array}$ & $z[-]$ & $\mathrm{m}[\mathrm{mm}]$ & $\mathrm{x}[-]$ & $\beta\left[^{\circ}\right]$ & $\mathrm{b}[\mathrm{mm}]$ & $\mathrm{d}[\mathrm{mm}]$ \\
\hline Sun & +11 & \multirow{3}{*}{1.25} & +0.5 & \multirow{3}{*}{0} & \multirow{3}{*}{20} & 13.75 \\
\hline Planet & +48 & & +0.30 & & & 60 \\
\hline Ring & -109 & & +0.437 & & & 136.25 \\
\hline
\end{tabular}

Tab. 1. Dimensions of the gears

\subsection{Initial conditions}

The planetary system should withstand a moment of $\mathrm{T}=343.75 \mathrm{Nmm}$ applied on the sun (Fig. 2). The maximum Hertzian pressure $\sigma_{\mathrm{H}}$ should not exceed $1500 \mathrm{MPa}$ and the maximum von Mises stress at the tooth foot $\sigma_{\mathrm{F}}$ was set to $1000 \mathrm{MPa}$. All the gears are made from case hardened steel with the following properties: specific mass $\rho=7850 \mathrm{~kg} / \mathrm{m}^{3}$, Poisson's ratio $v=0.3$, Young modulus $E=200 \mathrm{GPa}$, allowable contact stress $\sigma_{\mathrm{Hlim}}=1500 \mathrm{MPa}$ and allowable tooth-root stress $\sigma_{\text {Flim }}=1000 \mathrm{MPa}$. Due to the relatively small diameter of the sun gear, it is assumed that it is manufactured from a solid disc. This assumption is reasonable for planetary gear trains with high transmission ratio and also simplifies the analysis.

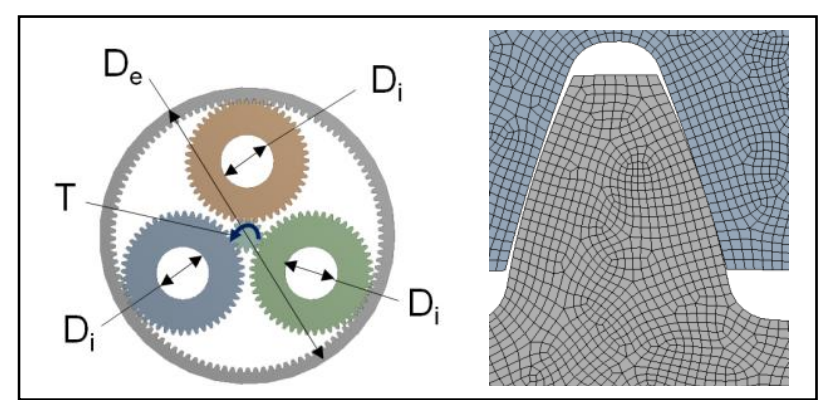

Fig. 2. Parameter definition and mesh detail 


\subsection{Model preparation and parameter definition}

The model of the assembly was created using a parametric ProEngineer procedure which took into account the manufacturing process when generating the gear tooth profiles. The geometry was completed in Autodesk Inventor. The parameters for the optimization study were defined in the solver preprocessing system and they were: the external diameter of the ring gear, the internal diameters of the planets and the output torque (Fig. 2). Response parameters were considered the maximum equivalent (von Mises) stress in the contact region of the gears, the maximum equivalent (von Mises) stress at the tooth root and the total weight.

The multiciteria optimization presumes an integrated CADCAE environment, where the regeneration of the geometry has to be done in a simple, fast and accurate way. Because it plays a key role in the nonlinear optimization loop, mesh generation (Fig.2) was tuned with the optimization strategy.

\section{OPTIMIZATION PROCEDURE AND RESULTS}

The optimization was performed in ANSYS using the Design of Experiments (DOE) technique solved for a central composite design. Afterwards Response Surfaces, Sensitivity analysis and Goal driven optimization tools were employed. The design parameters were varied continuously over given ranges and the performance of the assemblies was examined over these ranges.

Figure 3 shows one of the examined Response Surfaces for the safety factor, in respect to the planet gear diameter and the output torque. The multi-objective search used samples generated by the default screening method and the best candidates were classified and identified reducing the Parreto fronts. Since this is a decision support process on samples generated through the Hammersley technique and the solution is not unique, many multi-objective searches were run.

The external diameter of the ring was decreased to $143 \mathrm{~mm}$ and the internal diameter of the planets was increased to 150 $\mathrm{mm}$. The total weight of the planetary system was found $16 \%$ lower for variant $\mathrm{A}$ and $57 \%$ for variant $\mathrm{B}$ accordingly. The maximum output torque remained close to the initial value for candidate A, but decreased $31 \%$ for candidate B. Figure 4 shows a zoom in the trade-off plot where candidate A was identified.

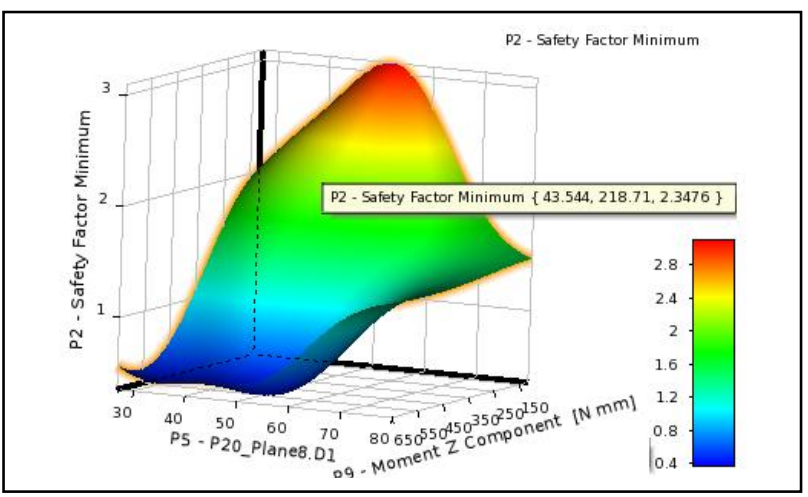

Fig. 3. Response Surface for the safety factor

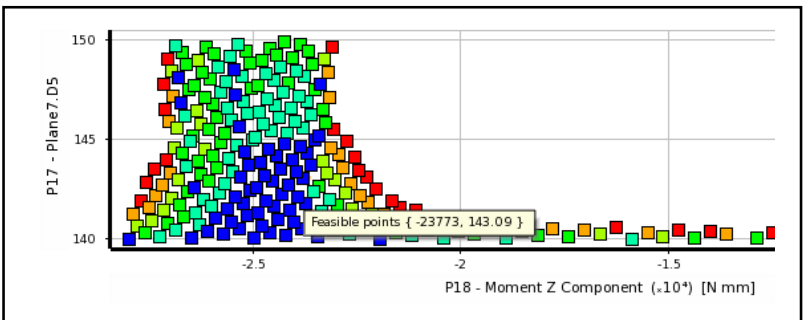

Fig. 4. Trade-off plot for candidate A

\section{ANALYTICAL CALCULATION AND MODEL VALIDATION}

The accuracy of the FEM results was verified by comparing the nominal values of the Hertzian pressure as well as the nominal tooth root stress, assuming a uniform load distribution to the three planets, i.e. $\mathrm{K}_{\gamma}=1$. The transmission ratio of the planetary gear system was $i=10.91$. The Hertzian pressure was calculated at the pitch point according to the ISO 6336 standard

$$
\sigma_{H 0}=Z_{H} Z_{E} Z_{\varepsilon} Z_{\beta} \sqrt{\frac{F_{t}}{d_{1} b} \frac{u+1}{u}}
$$

The contact ratio $Z_{\varepsilon}$ and the helix angle factor $Z_{\beta}$ were set to 1 , since $\beta=0^{\circ}$. The nominal tooth-root stress was also calculated according to the same standard

$$
\sigma_{F O-B}=\frac{F_{t}}{b m_{n}} Y_{F} Y_{S} Y_{\beta}
$$

The deviation between the theoretical and numerical values is less than $5.5 \%$. This is a satisfactory approximation because in the analytical calculation of the foot stress the tooth profile is approximated by a rack profile, according to the ISO 6336 standard. The accuracy may be easily improved when checking the best design solution.

\section{CONCLUSION}

The study dealt with a multi-criteria optimization strategy applied to a high ratio planetary system. Using a limited number of simulations, many design variants were analyzed and various optimization criteria were fulfilled. Because the solution is not unique, a "trade off" between parameters was carried out. Improved design variants for the rim thickness of the ring gear and for the internal diameters of the planet gears were found. The optimization attempt didn't take into account the deformation of the ring gear and of the planets, which play an important role in the behavior of the assembly. Future work will be focused on a more complete approach, including these additional parameters, as well as the load distribution and the number of the planets.

\section{REFERENCES}

ANSYS 12 (2009). Theory Reference. Swanson Analysis Sys, Inc., Jonson Road P.O. Box 65, Houston, U.S.A

Jahn, C. (1997). Theoretische und experimentelle Untersuchungen zur Zahnfußtragfähigkeit von Innenverzahnungen, Dissertation, TU Dresden

Kapelevich, A.L.; Shekhtman, Y.V.: Direct Gear Design: Bending Stress Minimization. Gear Technology, Sept./Oct. 2003, Available from: www.geartechnology.com, www.powertransmission.com. Accessed on: 2010-02-12

Linke, H.; Trempler, U.; Baumann, F. (2005). Analysis on the stress of toothings of planetary gearings, Available from: http://www.me.tu-dresden.de/publika/lit/LinBauTre05+.pdf Accessed on: 2010-04-20

Nan, G.; Zhang J. (2008). Finite Element Analysis of Internal Gear in High-Speed Planetary Gear Units, In: Transactions of Tianjin University, Tianjin Univ. \& Springer Verlag, Vol. 14, No. 1, pp.11-15

Simpson, W.T.; Lin, D.K.J.; Chen, E. (2001). Sampling Strategies for Computer Experiments. Design and Analysis. In: International Journal of Reliability and Safety, Vol. 2, No. 3, 2001, pp. 209-240

Winter, H.; Podlesnik, B. (1983). Zahnfedersteifigkeit von Stirnradpaaren, Teil 1 Antriebstechnik 22 (1983), pp. 39-42, Teil 2 Antriebstechnik 22 (1983) pp. 51-58, Teil 3 Antriebstechnik 23 (1984), pp. 43-49 